\title{
СЕМЬЯ, СОЦИАЛЬНЫЕ УСТАНОВКИ И АСОЦИАЛЬНОЕ ПОВЕДЕНИЕ ДЕТЕЙ И ПОДРОСТКОВ
}

\author{
Реан Артур Александрович
}

Рассматриваются вопросы взаимосвязи социальных установок и асоциального поведения детей и подростков. Анализируется вопрос о взаимосвязи установки и сочиального поведения в связи с такими факторами, как сила/ слабость, четкость/амбивалентность установки, а также влияние фрактора ситуации. Рассматриваются результаты эмпирических исследований ченностных ориентаций, морально-психологических установок молодежи на выборках старшеклассников и студентов. Семья рассматривается как фактор, одновременно обусловливающий как формирование социальных установок, так и самого асоциального поведения. Анализируются современные подходы и результаты эмпирических исследований условий, при которых сочиальные установки личности непосредственно влияют на асоциальное поведение, а при которых нет. Обсуждаются вопросы влияния на асочиальное поведение детей и подростков структурной и психологической деформачии семьи. Подчеркивается, что в плане детерминации асоциального поведения несовершеннолетних приоритет принадлежит психосоциальной деформации семьи. Показано, какие стили родительского воспитания и при каких условиях непосредственно влияют на формирование агрессивного поведения. Отмечается, что недостаточный надзор за ребенком является более важным фактором делинквентности, чем неблагоприятное социально-экономическое положение. Анализируются результаты эмпирических исследований, из которых следует, что важным условием развития социально отклоняющегося поведения является не только негативное социальное научение, но и фрустрация, возникающая при отсутствии родительской любви. Показано, что чентральное место в системе отношений детей и подростков принадлежит матери. Установлено, что снижение положительного отношения к матери, увеличение негативных дескрипторов при описании матери коррелирует с общим ростом негативизации всех социальных отношений личности. Подчеркивается, что взаимоотношения между родителями и ребенком, характеризуемые непоследовательностью, так же как и высокая конфликтность, наиболее значительно способствуют научению ребенка агрессии как способу разрешения межличностных конфликтов.

Ключевые слова: агрессия, асоциальное поведение, делинквентность, нейротичная экстраверсия, принцип агрегации, семья, сочиализация, социальные установки, спланированное поведение. 
Традиционно принято говорить о семье как факторе защиты развивающейся личности. Но в контексте настоящей работы хотелось бы также акцентировать внимание на возможных деструктивных влияниях семьи на развитие личности и рассмотреть семью как фактор риска социально девиантного поведения и развития личности. К семьям с психосоциальными нарушениями следует относить семьи с проблемами алкоголизации и наркомании, асоциальными ценностями, противоправным поведением, с высоким уровнем конфликтности, семьи, практикующие агрессивное поведение и насилие над ребенком, семьи с эмоциональной депривацией ребенка. Многие семейные нарушения коррелируют с асоциальным поведением подростков, что подтверждается данными статистики и специальных исследований.

В большинстве случаев за любым асоциальным поведением стоит искаженная в морально-психологическом плане картина мира, искаженные, асоциальные установки. Конечно, современной психологии известно, что между установками личности и ее поведением нет абсолютной зависимости. Однако радикальные выводы об отсутствии связи установки с поведением, и соответственно, о невозможности прогнозировать поведение на основе установок личности, которые появились после известного эксперимента P. Ла Пьера (La Pier, 1934), к настоящему времени претерпели существенные изменения и уже не являются столь радикальными и однозначными, что следует из работ М. Хьюстона, В. Штребе [21], Д. Майерса [12], Г. М. Андреевой [1], А. Л. Свенцицкого [17] и др. В настоящее время считается доказанным, что важным условием соответствия установки и поведения является то, чтобы установка личности была достаточно сильной и четкой. Несоответствие же чаще всего наблюдается в случаях, когда установка является слабой или амбивалентной, или и той, и той одновременно. Важную роль, конечно, играет и фактор ситуации. В тех случаях, когда ситуация оказывает сильное давление на личность, имеющаяся установка может и не сработать. Как установлено в работах Д. Майерса [12], М. Хьюстона, В. Штребе [21], одним из важных положений современной психологии установки является определение принципа агрегации: воздействие установки на поведение становится более четким и очевидным, когда мы рассматриваем личность и поведение в целом, а не какой-либо отдельный поступок. Иллюстрацией этого принципа, например, являются результаты следующего исследования. Как оказалось, имеющаяся установка на сохранение окружающей среды в городе своего проживания коррелировала, но слабо, с отдельными актами поведения жителей, участвующих в эксперименте: подписать одно из воззваний против выхлопных газов, выйти в конкретный день на уборку мусора, привлечь друга к такой работе и т. п. Но совокупная оценка «экологического» поведения по 16 позициям (которые соответствовали различным актам поведения), как показано 


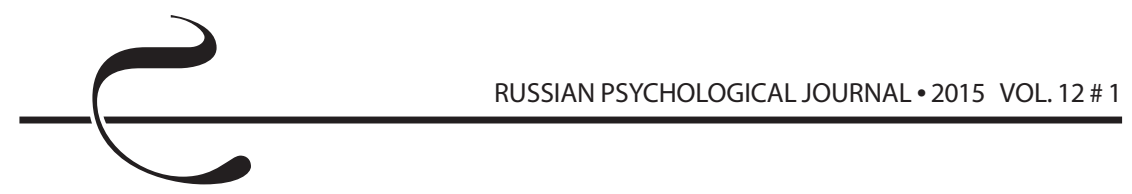

в работах R. H. Weigel \& L. S. Newman, M. Хьюстона, В. Штребе [21], уже дает высокую $(p \leq 0,001)$ корреляцию между установкой и поведением.

Таким образом, из всего этого следует только то, что определенные установки не всегда выражаются в соответствующем поведении. Чаще по причине того, что действуют определенные сдерживающие факторы. Некоторые авторы насчитывают до 40 различных факторов, осложняющих связь в паре установка-поведение, на что обращают внимание, например, Д. Майерс [12], H. Triandis. Вместе с тем, если определенное асоциальное поведение имеет место быть, то за ним стоят и соответствующие установки личности, обусловливающие готовность личности к такому асоциальному поведению. Исключения составляют лишь случаи непредумышленного, случайного делинквентного поступка или поступка под сильным ситуационным давлением. Подчеркнем принципиальный момент - именно поступка, а не систематического девиантного, делинквентного поведения личности. Или, как было замечено Ральфом Уолдо Эмерсоном (Ralph Waldo Emerson) еще в 1841 г.: «Любое действие рождается от мысли».

В этом контексте, результаты некоторых исследований ценностных ориентаций, морально-психологических установок молодежи не могут не настораживать. Так, в одном из таких исследований старшеклассников попросили отметить те поговорки, которые наиболее точно отражают их жизненную позицию (в списке предлагалось 40 пословиц и поговорок, из которых ребята должны были отметить лишь 10, наиболее близких им). Выборочную совокупность составили более 1700 человек в возрасте 14-17 лет из всех районов одной из областей центральной России. Выборка была репрезентативной по половому, возрастному и социальному составу старшеклассников.

Вот наиболее часто отмечаемые пословицы, точнее всего характеризующие жизненную позицию старшеклассников. «В отношениях с другими людьми я придерживаюсь поговорки...»: «Что наша честь, если нечего есть?» (93 \%); «Работа - не волк, в лес не убежит» (93\%); «От трудов праведных не нажить палат каменных» (93 \%); «С волками жить - по-волчьи выть» (83\%); «Стыд - не дым, глаза не выест» (81 \%); «Своя рубашка ближе к телу» (79\%); «Скупость - не глупость» (76 \%); «Не делай добра - не получишь зла» (73\%); «Говоришь правду - теряешь дружбу» (67 \%); «Две собаки грызутся - третья не лезь» (48\%)... Обращает на себя внимание и то, что значительная часть достаточно известных пословиц и поговорок русского народа, в которых выражается традиционная социальность, не получили массовой поддержки у старшеклассников и оказались по количеству их отметивших на последних позициях: «Не имей 100 рублей, а имей 100 друзей» (9 \%); «Правда - в огне не горит и в воде не тонет» (3 \%); «Где родился - там и пригодился» (3\%); «Для Родины своей ни сил, ни жизни не жалей» (2\%); «Родина - мать, умей 
за нее постоять» (2 \%); «Чужое добро впрок не пойдет» (2 \%); и всего по одному человеку - «Бедность - не порок»; «Не в деньгах счастье» (М. Коротких, 2009) [11].

Практически абсолютно такие же результаты были получены и на выборке студентов. Различия, да и то совсем небольшие, были лишь в числовых показателях процентов, но никак не касались самой иерархии ценностей, предпочтений, жизненных позиций. Вот наиболее часто отмечаемые пословицы, точнее всего характеризующие жизненную позицию студентов. «В отношениях с другими людьми я придерживаюсь поговорки...»: «От трудов праведных не нажить палат каменных» (89\%); «Что наша честь, если нечего есть?» (83 \%); «Своя рубашка ближе к телу» (73 \%); «Работа - не волк, в лес не убежит» (73 \%); «С волками жить - по-волчьи выть» (71 \%); «Стыд - не дым, глаза не выест» (69\%); «Скупость - не глупость» (66 \%); «Не делай добра - не получишь зла» (63 \%); «Говоришь правду - теряешь дружбу» (61%); «Две собаки грызутся - третья не лезь» (58 \%). Значительная часть достаточно известных пословиц и поговорок, выражающих традиционную социальность русского человека, не получили поддержки студентов и оказались по количеству их отметивших на последних позициях: «Не имей 100 рублей, а имей 100 друзей» (12\%); «Правда - в огне не горит и в воде не тонет» (6\%); «Где родился - там и пригодился» (5 \%); «Для Родины своей ни сил, ни жизни не жалей» (1 \%); «Родина - мать, умей за нее постоять» (1 \%); «Чужое добро впрок не пойдет» (1 \%); «Бедность - не порок» (2 человека); и один человек - «Не в деньгах счастье» (И. Булатников, 2009) [7].

Это, несомненно, не только тревожные, но и шокирующие результаты. Несколько позволяет сгладить шок, пожалуй, то обстоятельство, что по теории установки наиболее сильно и прямо определяют только спонтанное поведение личности. С так называемым продуманным или спланированным поведением, к счастью, дело обстоит несколько сложнее. Теория спланированного поведения - I. Ajzen [24], I. Ajzen \& M. Fishbein [25] - утверждает, что спланированное, преднамеренное поведение точнее и лучше всего определяют не один, а три фактора (или составляющие): установки личности по отношению к конкретному поведению, к субъективным нормам, к возможностям контроля своих действий. Первый фактор связан с утверждением, что для прогноза поведения личности важна не общая установка, а конкретная установка, т. е. конкретное отношение человека к поступку, о котором он думает. Второй фактор позиционирует то, что для успешного предсказания конкретного поведения человека необходимо знать субъективные нормы т. е. его представления о том, как близкие ему люди воспримут, отнесутся к планируемому поступку. И, наконец, третий фактор связан с представлением человека о легкости, с которой он может совершить тот или иной поступок. 
Э. Аронсон, Т. Уилсон, Р. Эйкерт подчеркивают, что если человеку кажется, что поступок совершить трудно, то тогда намерение совершить такой поступок серьезно ослабевает; если же человек считает, что определенный поступок совершить легко, то тогда возникает сильное желание именно так и поступить.

Таким образом, представление подростка об отрицательном отношении семьи, родителей, близких к поступку, побуждаемому вышеуказанными негативными установками, снижает вероятность его осуществления. Но, с другой стороны, дело осложняется тем, что сами эти установки возникают все-таки не из пустоты, а формируются, в частности, в самой семье, в процессе семейной социализации. А, следовательно, они могут отражать и соответствовать установкам, господствующим в семье, у родителей и близких. Но в этом случае, в соответствии с теорией спланированного поведения, реализация поступков, которые соответствуют вышеуказанным негативным установкам, облегчается, становится более вероятной.

Долгое время считалось, что социально отклоняющееся развитие личности связано со структурной деформацией семьи, под которой понимается просто неполная семья - отсутствие одного из родителей (чаще отца). Статистические данные по преступности несовершеннолетних, полученные в разных странах мира, подтверждали этот вывод. Однако в 60-70-е гг. обнаружилась другая тенденция. Сначала разница между полными и неполными семьями по количеству «выдаваемых» ими подростков-правонарушителей стала неуклонно сокращаться, а затем и практически полностью исчезла. В настоящее время считается, что основным фактором негативного влияния семьи на развитие личности является не структурная, а психосоциальная деформация семьи. И это общемировая тенденция.

Вместе с тем, следует подчеркнуть, что структурная деформация семьи все-таки крайне нежелательна. Она вносит значительный вклад в развитие социальных девиаций личности, особенно если круг этих девиаций не сводить только к противоправному поведению. Да и по вкладу в делинквентность данные различных исследований все-таки достаточно противоречивы. Так, по данным одного из российских исследований в структурно деформированной (то есть неполной) семье проживает около 50 \% подростков-делинквентов. А, значит, вторая половина имеет полную семью. А вот проблемы с различными проявлениями психосоциальной деформации семьи, как установлено в работе В. В. Королева [10], оказываются характерными для более 70 \% процентов подростков-правонарушителей.

В целом же, когда мы говорим о разном вкладе в развитие асоциальности несовершеннолетних психосоциальной деформации и собственно структурной деформации семьи, надо отдавать себе отчет в том, что это не 
изолированно полярные категории. Психосоциальная деформация - понятие более широкое, чем структурная деформация. Ведь психосоциальная деформация может быть присуща как полной, так и неполной семье.

Связь между воспитанием ребенка в неполной семье и делинквентностью в значительной мере усложняется наличием многих других факторов. Например, вполне очевидно, существует зависимость между разводом и социально-экономическим статусом семьи. Но, как подчеркивается в работах R. J. Sampson \& W. J. Wilson, K. Бартола [5], обобщение данных многочисленных исследований четко показывает, что бедность является одним из наиболее надежных признаков, позволяющих прогнозировать подростковую преступность как среди юношей, так и среди девушек. Бедность влияет на семью по разным направлениям, одним из которых является возможное изменение поведения родителей. Так, стресс, обусловленный бедностью, как показано в работах W. R. Hammond \& B. R. Yung, K. Бартола [5], уменьшает способность родителей осуществлять благоприятное и непротиворечивое воспитание.

Недостаточный надзор за ребенком, характерный для т. н. безучастного стиля воспитания, присущ семьям как с высоким, так и с низким социальным статусом, как полным, так и неполным семьям. А вместе с тем, именно недостаточный надзор, как было установлено во многих исследованиях, значимо коррелирует с делинквентностью и с агрессией, о чем убедительно говорят S. Cerncovich \& P. C. Giorgano, Р. Блэкборн [6]. Более того, в исследованиях W. J. Wilson (1987) было показано, что плохой контроль со стороны матерей является более важным фактором в различении делинквентов и неделинквентов, чем неблагоприятное социально-экономическое положение или даже криминальность родителей [6].

Важнейшим механизмом негативного влияния семьи на развитие личности является социализация в семье по отклоняющемуся типу. Асоциальные ценности, нормы и стереотипы поведения могут усваиваться по механизму научения и подражания, если именно такие ценности и нормы являются доминирующими в данной семье. При этом закрепление социально отклоняющегося развития, как показано в работах А. Бандуры [3], А. Бандуры, Р. Уолтерса [4], Р. Бэрона, Д. Ричардсон [8] и др., может идти тремя путями: за счет прямого декларирования асоциальных ценностей и норм, и подчеркивания «что только так и можно достичь успеха»; за счет проявления асоциального поведения при непосредственном взаимодействии родителей с ребенком; за счет наблюдения ребенком в реальном поведении родителей социально отклоняющейся направленности, даже если на речевом уровне ими декларируется приверженность просоциальному поведению и просоциальной шкале ценностей. 
Формирование просоциального поведения личности связано не только с механизмами отсутствия подкрепления или активного наказания за асоциальное поведение, но и обязательно (и может быть, даже в первую очередь) с активным социальным научением просоциальным формам поведения, конструктивным способам разрешения противоречий и реализации различных мотиваций личности. Ведь как установлено в исследовании L. KeltikangasJarvinen, P. Kangas [28], наиболее выраженные различия между детьми с деструктивным и конструктивным социальным поведением обнаруживаются не в личностном предпочтении деструктивных альтернатив, а в незнании конструктивных решений. Таким образом, процесс социализации конструктивного поведения включает приобретение системы знаний и социальных навыков, а также воспитание системы личностных диспозиций, установок, на основе которых формируется способность реагировать на фрустрацию относительно приемлемым образом.

Другим важным механизмом влияния семьи на развитие социальных девиаций и асоциального поведения личности является эмоциональное пренебрежение ребенком, «неценностное» отношение к нему. Так называемый безучастный, или игнорирующий тип воспитания, при котором дети становятся «ловцами, искателями внимания», наиболее сильно связан с последующей делинквентностью. В некоторых исследованиях, о чем, например, пишет Р. Блэкборн [6], было установлено, что 84 \% детей, бывших «ловцами внимания» в восьмилетнем возрасте, в 14 лет имели дело с полицией. Существует огромное число исследований, которые убедительно показывают зависимость между негативными взаимоотношениями в системе «родители-ребенок», недостаточностью эмоциональности в семье и социально отклоняющимся развитием личности. Установлено, например, что если у ребенка сложились негативные отношения с одним или обоими родителями, если тенденции развития позитивности самооценки и Я-концепции не находят поддержки в оценках родителей, или если ребенок не ощущает родительской поддержки и опеки, то вероятность противоправного поведения существенно возрастает, ухудшаются отношения со сверстниками, проявляется агрессивность по отношению к собственным родителям.

Важнейшим условием эффективной социализации и предупреждения становления отклоняющихся форм поведения является развитие мотивации привязанности, посредством которой у ребенка появляется необходимость в интересе, внимании и одобрении окружающих, и в первую очередь - собственных родителей. В качестве вторичного подкрепления привязанность затем может обусловливать приспособление ребенка к социальным требованиям и запретам, т. е. к просоциальному поведению. В этой связи следует подчеркнуть, что важным условием развития социально отклоняющегося 
поведения является не только социальное научение как таковое, но и фрустрация, возникающая при отсутствии родительской любви и при постоянном применении наказаний со стороны либо одного, либо обоих родителей.

Особое место в системе отношений детей и подростков, конечно, принадлежит матери. Так, в одном исследовании А. А. Реана и М. Ю. Санниковой [16], было показано, что в системе отношений подростка к социальному окружению (в том числе определялось и отношение к отцу, а также к сверстникам) именно отношение к матери оказалось наиболее положительным. Было установлено, что снижение положительного отношения к матери, увеличение негативных дескрипторов (характеристик) при описании матери коррелирует с общим ростом негативизации всех социальных отношений личности. Можно полагать, что за этим фактом стоит фундаментальный феномен проявления тотального негативизма (негативизма ко всем социальным объектам, явлениям и нормам) у тех личностей, для которых характерно негативное отношение к собственной матери. В целом, как установлено в исследовании, негативное отношение к собственной матери является важным показателем общего неблагополучного развития личности.

В последние годы выявляется устойчивая тенденция снижения роли отца, его значимости и влияния на воспитание и становление личности ребенка. Так, в фундаментальном исследовании под названием «Семья и родительство в современной России» было установлено, что доля тех, кто назвал отца значимым лицом, оказавшим в процессе взросления на личность наибольшее влияние, снизилась с 41,1 \% (в старшей возрастной группе 40-44 года) до 31,8 \% (в молодежной группе 16-19 лет).

Чем слабее становилась фигура отца, тем более укреплялась в сознании респондентов фигура матери. В молодежной группе (16-19 лет) доля тех, кто оценивал роль матери как самую значительную, составила 73,3 \%, в то время как в старшей возрастной группе (40-44 года) - таких было 61,9% [18].

На роль отца в родительской семье влияет не только возраст, но и другие показатели.

Например, уровень достатка. В бедных семьях влияние отца отметили только 26,8 \% опрошенных, в семьях со средними или высокими стандартами жизни - 40,7 \%. Таким образом, восприятие отца в значительной степени зависит от того, насколько успешно он справляется с ролью кормильца семьи.

Респонденты с высшим образованием оценивали роль отца выше, чем респонденты со средним образованием (36,6 \% и 42,2 \% соответственно). Однако эти различия оказались незначимыми [18].

На сегодняшний день пожалуй уже не вызывает сомнения, что между строгостью наказания родителями своих детей и уровнем агрессивности детей существует положительная зависимость. 
Эта зависимость, как оказалось, распространяется и на случаи, когда наказание является реакцией родителей на агрессивное поведение ребенка. То есть используется в качестве воспитательной меры, направленной на снижение агрессивности и формирование неагрессивного поведения ребенка.

В одном эксперименте изучалось агрессивное поведение детейтретьеклассников в связи особенностями стратегий родительского наказания (L. D. Eron at al., 1963). К первому уровню реагирования (который, строго говоря, и наказанием-то назвать нельзя) относили просьбы вести себя по-другому и поощрения за изменение поведения. Ко второму уровню наказаний (умеренные наказания) относили словесное порицание, выговоры, брань. К третьему уровню наказаний (строгие наказания) относили физическое воздействие, шлепки, подзатыльники. В результате исследования было обнаружено, что те дети, которые подвергались со стороны родителей строгим наказаниям, проявляли в поведении большую агрессию, и соответственно, характеризовались одноклассниками как агрессивные.

В другом исследовании R. B. Felson, N. Russo [27] было показано также, что вмешательство родителей при агрессии между братьями-сестрами может на самом деле оказывать обратное действие и стимулировать развитие агрессии. Нейтральная позиция родителей, как следует из этого исследования, оказывается предпочтительной. Самой неэффективной стратегией оказывается вмешательство родителей в форме наказания старших сибсов, т. к. в этом случае уровень как вербальной, так и физической агрессии в отношениях между братьями-сестрами оказывается наиболее высоким. Сходные результаты были получены и в других исследованиях, таких например, как исследование G. Patterson [29].

Обобщение результатов подобных исследований приводит специалистов к формулированию предложения относиться к агрессии между сибсами особым образом - игнорировать ее, не реагировать на агрессивное взаимодействие братьев-сестер. Однако такой вывод представляется все-таки слишком радикальным. Иногда не реагировать на агрессию во взаимодействии братьев-сестер родителям просто невозможно, а подчас и прямо вредно и небезопасно. В ряде ситуаций (например, когда агрессивное взаимодействие между сибсами уже не является редким исключительным случаем) нейтральная позиция родителей может только способствовать дальнейшей эскалации агрессии. Более того, такая позиция может создавать благоприятные условия для социального научения агрессии, закреплению ее как устойчивого поведенческого паттерна личности, что имеет уже долгосрочные негативные последствия. 
В исследовании, о котором мы говорили выше, изучались лишь две альтернативы реагирования родителей на агрессию между братьями-сестрами: (1) нейтральная позиция, т. е. игнорирование фактов агрессии и (2) наказание детей (в одном варианте - старших, в другом - младших). Очевидно, при такой суженной альтернативе нейтральная позиция действительно оказывается относительно (и только относительно) лучшей. Однако возможны и другие, альтернативные способы родительского реагирования на агрессию между сибсами, которые не были здесь предметом изучения. Одним из таких способов реагирования является обсуждение возникшей проблемы, осуществление переговорного процесса, научение на конкретном примере возникшего конфликта конструктивным, неагрессивным способам его разрешения. Ведь, как экспериментально доказано в других исследованиях, агрессивные дети отличаются от неагрессивных в первую очередь именно слабым знанием конструктивных (альтернативных агрессивным) способов разрешения конфликтов.

Наиболее полной моделью неэффективных родительских приемов дисциплинирования, которая очень влиятельна в данной области исследований, считается теория «принудительного семейного процесса» Дж. Р. Паттерсона (G. R. Patterson, 1982; G. R. Patterson, J. B. Reid, T. J. Dishion, 1992; Д. Коннор [9]). Эта модель исходит из того, что обмены жесткими и, что особенно важно, непоследовательными, несогласующимися действиями между родителями и ребенком в конфликтах по вопросам дисциплины приводят к агрессии или асоциальному поведению ребенка. Взаимоотношения между родителями и ребенком, характеризуемые непоследовательностью - сначала слабость, затем жесткость - так же, как и высокая конфликтность, наиболее значительно способствуют научению ребенка агрессии как способу урегулирования межличностных конфликтов.

В этой связи, интересным представляется тот факт, что лучшим прогностическим признаком задержания за правонарушения в возрасте 10-13 лет оказалась «недисциплинированность» в более раннем возрасте. По-другому дело обстоит в более старшем возрасте. Осуждение за правонарушения в возрасте 17-20 лет точнее всего прогнозируется, как оказалось, по таким факторам, как агрессивность в возрасте 12-14 лет и уровень нейротичной экстраверсии в возрасте 16 лет, - как показано в работе А. Фернхем, П. Хейвен [20].

В современной психологической науке, в рамках одной из наиболее авторитетных концепций личности, автором которой является А. Маслоу, принято считать, что потребность в любви и уважении является одной из фундаментальных потребностей личности. И она входит в пятерку основных, базовых потребностей человека, наряду с потребностями выживания - т. е. физиологическими и потребностью в безопасности. 
В связи с этим, обратим внимание на следующие чрезвычайно важные, на наш взгляд, обстоятельства. В 60-е гг. в США приобрело популярность течение, связанное с таким воспитанием, когда родители минимально вмешиваются в жизнь ребенка, предоставляя ему максимальную свободу в принятии решений и, собственно, в жизни. Предполагалось, что это есть выражение уважения личности ребенка, вроде как либеральнодемократический подход в практике воспитания. Однако психологические исследования, проведенные спустя годы, показали, что именно дети из этих семей имели во взрослой жизни больше проблем. И, что особенно показательно, - именно дети, выросшие в этих семьях, как подчеркивают П. Массен, Дж. Конджер и др., отмечали наибольшую неудовлетворенность своим семейным детством [13].

То есть оказалось, что предоставленная родителями свобода в конце концов воспринималась не как особое доверие и уважение к личности ребенка, а как недостаток или даже отсутствие родительской любви и заботы.

\section{Литература}

1. Андреева Г. М. Социальная психология. - М., 1988.

2. Аронсон Э., Уилсон Т., Эйкерт Р. Социальная психология. Психологические законы поведения человека в социуме. - М., 2002.

3. Бандура А. Теория социального научения. - СПб., 2000.

4. Бандура А., Уолтерс Р. Подростковая агрессия. Изучение влияния воспитания и семейных отношений. - М., 2000.

5. Бартол К. Психология криминального поведения. - СПб., М., 2004.

6. Блэкборн Р. Психология криминального поведения. - СПб., 2004.

7. Булатников И. Е. Развитие социальной ответственности личности: место и роль семьи / Процветающая Россия - будущее твоей семьи (Материалы проекта по гранту Президента РФ). - Курск, 2009. - С. 252-264.

8. Бэрон Р., Ричардсон Д. Агрессия. - СПб., 1997.

9. Коннор Д. Агрессия и антисоциальное поведение у детей и подростков. - М., СПб., 2005.

10. Королев В.В. Психические отклонения у подростков-правонарушителей. М., 1992.

11. Коротких М. Н. Развитие гражданского самосознания юношества в совместной деятельности семьи и школы: векторы перемен / Процветающая Россия - будущее твоей семьи (Материалы проекта по гранту Президента РФ). - Курск, 2009. - С. 135-147.

12. Майерс Д. Социальная психология. - СПб., 1997.

13. Массен П., Конджер Дж., Каган Дж., Хьюстон А. Развитие личности ребенка. - М., 1987. 
14. Реан А. А. Детская агрессия / Психология человека от рождения до смерти. Под ред. А. А. Реана. - СПб., 2006. - С. 305-312.

15. Реан А. А. Подростковая агрессия / Психология подростка. Под ред. А. А. Реана. - СПб., 2007. - С. 324-337.

16. Реан А. А. Психология личности. - СПб., 2013.

17. Свенцицкий А. Л. Социальная психология. - М., 2003.

18. Семья и родительство в современной России. - М., 2009.

19. Семья: психология, педагогика социальная работа. Под ред. А. А. Реана. - М., 2010.

20. Фернхем А., Хейвен П. Личность и социальное поведение. - СПб., 2001.

21. Хьюстон М., Штребе В. Введение в социальную психологию. Европейский подход. - М., 2004.

22. Шнейдер Л. Б. Девиантное поведение детей и подростков. - М., 2007.

23. Эмерсон Р. У. Нравственная философия. Опыты. - М., 2001.

24. Ajzen I. From intentions to actions: A theory of planed behavior // Actioncontrol: from cognition to behavior. - 1985. - pp. 11-39.

25. Ajzen I. \& Fishbein M. Understanding attitudes and predicting social behavior. - NJ., 1980.

26. Eron L. D., Walder L. O., Toigo R., Lefkowitz M. M. Social class, parental punishment for aggression and child aggression // Child Development. - 1963. 34. - pp. 849-867.

27. Felson R. B., Russo N. Parental punishment and sibling aggression // Social Psychology Quarterly. - 1988. - 51. - pp. 11-18.

28. Keltikangas-Jarvinen L., Kangas P. Problem-solving strategies in aggressive and nonaggressive children // Aggr. Behav. - 1988. - no. 4. - pp. 255-264.

29. Patterson G. R., Stouthamer-Loeber M. The correlation of family management practices and delinquency // Child Development. - 1984. - 55. pp. 1299-1307. 